\title{
Anophthalmia with cleft palate and micrognathia: a new syndrome?
}

\author{
Shubha R Phadke, Anita K Sharma, S S Agarwal
}

\begin{abstract}
A 5 day old male with bilateral anophthalmos, hypospadias, bifid scrotum, micrognathia, and cleft palate with normal chromosomes is described. There have been two case reports with similar clinical manifestations but associated with interstitial deletion of $14 \mathrm{q}$ (q22q23). ${ }^{12}$ We propose that either our patient represents a new syndrome or has a microdeletion which could not be detected on routine cytogenetics. High quality cytogenetics and FISH may show microdeletions in patients presenting with this clinical picture and normal chromosomes.
\end{abstract}

(f Med Genet 1994;31:960-961)

We describe here a neonate with bilateral anophthalmos in association with Pierre Robin anomaly, abnormal genitalia, and normal chromosomes. Clinical features similar to those of our patient have been described previously in two patients with an interstitial deletion of $14 \mathrm{q}(\mathrm{q} 22 \mathrm{q} 23)$.

\section{Case report}

A 5 day old male child, born at term, was referred to the genetic clinic with bilateral anophthalmos. The antenatal period had been uneventful. Family history was negative for a

\footnotetext{
Department of Medical Genetics, Sanjay Gandhi Post Graduate Institute of Medical Sciences, Raebareli Road, Lucknow 226014 , Luckn

S R Phadke

A K Sharma

S S Agarwal

Correspondence to Dr Sharma.

Received 17 March 1994 Revised version accepted fo publication 1 June 1994
}

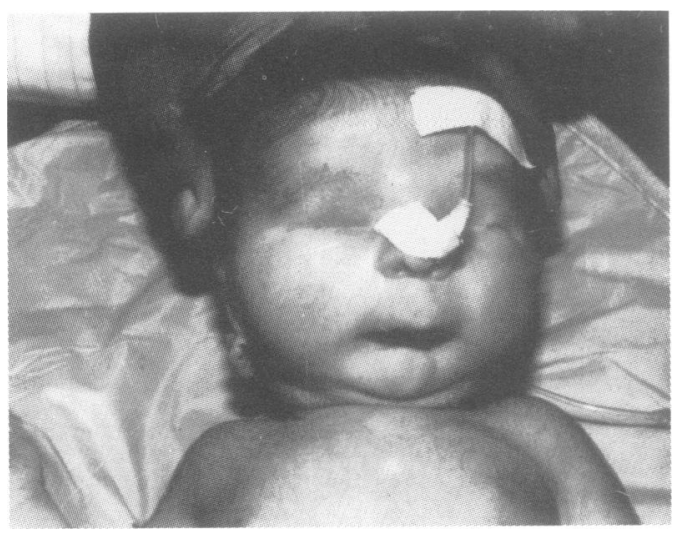

Figure 1 Proband showing anophthalmos.

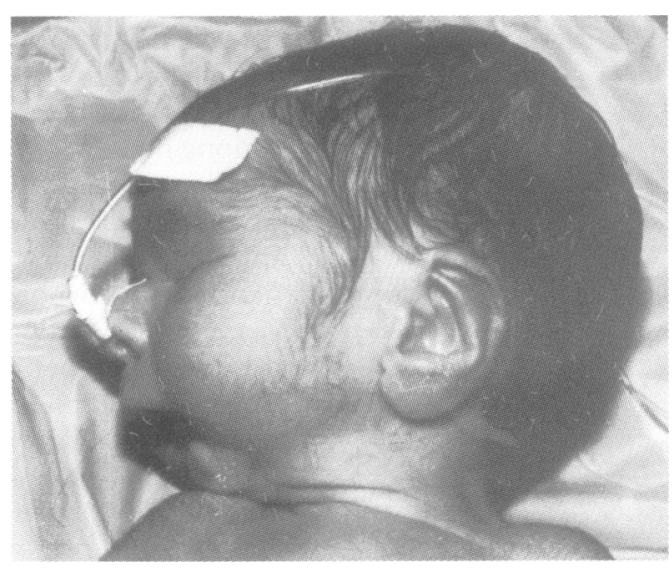

Figure 2 Proband showing micrognathia.

similar disorder. The birth weight of the child was $2100 \mathrm{~g}$, length $44 \mathrm{~cm}$ (both less than the 3 rd centile), and head circumference $34 \mathrm{~cm}$ (50th centile).

The child had bilateral anophthalmos (fig 1). The eyelids appeared to be adherent. No cornea or eyeball could be seen on forcibly opening the eyelids. The lacrimal puncta were absent. There was severe retrognathia (fig 2) and a " $U$ " shaped cleft palate involving both the soft and hard palates. The philtrum was long and smooth. The ears were large, flat, and posteriorly rotated. There was bilateral clinodactyly and simian crease. The child had perineal hypospadias, a bifid scrotum, and a right inguinal hernia. The testes were descended on both sides. Tone and neonatal reflexes were normal. Radiographs of the whole body and skull, echocardiogram, and ultrasound of the kidneys, liver, and brain were all normal. The karyotype of the child was $46, \mathrm{XY}$ on routine $\mathrm{G}$ banding. On follow up the child was not thriving. His weight in the fifth month was $3.5 \mathrm{~kg}$ and he had not achieved neck control. He died at home at the age of 5 months. No necropsy was carried out.

\section{Discussion}

We have described a patient with bilateral anophthalmos, micrognathia, cleft palate, malformed ears, digital anomalies, abnormal 
Comparison of our patient with reports of $14 q$ deletion

\begin{tabular}{|c|c|c|c|}
\hline \multirow[b]{2}{*}{ Clinical features } & \multicolumn{2}{|c|}{ Deletion $14 q(q 22 q 23)$} & \multirow[b]{2}{*}{ Our patient } \\
\hline & Bennett et al ${ }^{l}$ & Elliott et al ${ }^{2}$ & \\
\hline Micro/anophthalmos & + & + & + \\
\hline Blepharophimosis & + & + & + \\
\hline Microcephaly & \pm & + & + \\
\hline Retardation & $\bar{N} A$ & + & + \\
\hline Ear abnormalities & + & + & + \\
\hline Cleft lip/palate & - & High arched & + \\
\hline Dental anomalies & NA & + & - \\
\hline Skeletal anomalies & - & - & - \\
\hline Digital anomalies & + & - & + \\
\hline Urogenital anomalies & + & + & + \\
\hline Family history & - & - & - \\
\hline Micrognathia & + & + & + \\
\hline Other anomalies & $\begin{array}{l}\text { Hypoplastic } \\
\text { kidneys, } \\
\text { hypoplastic } \\
\text { adrenals, absent } \\
\text { pituitary }\end{array}$ & Hypothyroid & - \\
\hline
\end{tabular}

external genitalia, and normal chromosomes.

Bennett et $a l^{1}$ described a patient with similar clinical manifestations including anophthalmia, micrognathia, abnormal genitalia, and failure to thrive. The chromosomes showed an interstitial deletion of $14 \mathrm{q}$ (q22q23). Deletion of the same region with a similar clinical picture associated with an absent pituitary fossa has been described previously in a female fetus. ${ }^{2}$ The clin- ical picture of our patient compared with these two case reports is shown in the table.

Another condition that bears some resemblance to our patient is the X linked Lenz syndrome. This is characterised by anophthalmos/microphthalmos, developmental retardation, and aural, digital, skeletal, and urogenital anomalies. ${ }^{34}$ However, the Pierre Robin anomaly, that is, micrognathia with cleft palate, which is a feature of our patient is not part of the Lenz syndrome.

We propose that the patient presented here represents a new syndrome of anophthalmia, cleft palate, and micrognathia. However, the possibility of a microdeletion of $14 \mathrm{q}$ cannot be ruled out with certainty. It is thus desirable to perform high quality cytogenetics and FISH in such cases.

1 Bennett CP, Betts DR, Seller MJ, Deletion 14q (q22q23) associated with anophthalmia, absent pituitary and other abnormalities. ₹ Med Genet 1991;28:280-1.

2 Elliott J, Maltby EL, Reynolds B. A case of deletion 14q (q22.1q22.3) associated with anophthalmia and pituitary abnormalities. F Med Genet 1993;30:251-3.

3 Traboulski EI, Lenz W, Gonzales-Ramos M, Siegel J, Macrae WG, Maumenee LH. The Lenz microphthalmia syndrome. Am f Ophthalmol 1988;105:40-5.

4 Baraitser M, Winter RM, Taylor DS. Lenz microphthalmia: a case report. Clin Genet 1982;22:99-101. 